\section{Imitational and social facilitatory aspects of observational learning in the laboratory rat*}

\author{
ELIOT L. GARDNER † \\ Albert Einstein College of Medicine, Bronx, N.Y. 10461 \\ and \\ DENNIS R. ENGEL \\ Comparative Psychology Division, 6571st Aeromedical Research Laboratory \\ Holloman Air Force Base, N. Mex. 88330
}

Rats acquired a food-motivated leverpressing response by "observational learning" or by trial-and-error learning under conditions of social facilitation or isolation. Both the observational learning and social facilitation Ss learned faster than did the isolated trial-and-error Ss. There was no difference in speed of learning between the observational learning and social facilitation groups. It is suggested that some previous studies purporting to demonstrate observational learning may have demonstrated socially facilitated trial-and-error learning instead.

As recently noted by Groesbeck \& Duerfeldt (1971), the relevant variables needed to successfully produce observational learning in laboratory animals are poorly understood. In fact, the very existence of observational learning in nonprimate species remains a matter of some debate. An extensive body of pre-1935 work, reviewed by Warden \& Jackson (1.935), produced predominantly negative results. More recently, a number of investigators (e.g., Church, 1957; Corson, 1967; Groesbeck \& Duerfeldt, 1971; John et al, 1968; Stimbert et al, 1966) have reported positive findings of observational learning in both rats and cats. Other recent workers, however, have failed to obtain observational learning under a variety of conditions in both rats and birds (Gilbert \& Beaton, 1967; Klopfer, 1959; Powell, 1968; Sexton \& Fitch, 1967).

In spite of these inconsistent findings, the importance of observational learning as an example of vicarious process learning and its implications for the nature of the brain mechanisms subserving learning continue to make it a subject of interest and importance (Bandura, 1962; John et al, 1968). Of possible relevance to research on observational learning is the fact that the mere presence of another animal in a learning situation can lead to an increase in general arousal and general activity or to fear reduction (Davitz \&

* Supported by USPHS Grant 5T01-GM 00065 to E.L.G, and by various funds from the 6571st Aeromedical Research Laboratory, Holloman AFB, N. Mex. We thank W. E. Bacon for the initial inspiration. We also thank $D . N$ Farrer and C. H. Kratochvil for unstinting support.

tRequests for reprints may be sent to Eliot L. Gardner, Albert Einstein College of Medicine, 1300 Morris Park Avenue, New York. N.Y. 10461.
Mason, 1955; Hughes, 1969; Latané, 1969; Tolman, 1968; Treichler et al, 1971; Zajonc, 1965). Since such conditions may well enhance trial-and-error learning, it is possible that the inconsistency in reports of observational learning may be due in part to inadequate differentiation between direct imitation and social facilitation of conventional trial-anderror learning.

The experiment reported here specifically compared "observational learning" of a leverpressing response by laboratory rats with socially facilitated trial-and-error learning of the same response.

\section{METHOD}

The Ss were 60 male hooded Long-Evans rats, each weighing no less than $300 \mathrm{~g}$. They were housed in standard laboratory cages, two animals per cage, with water freely available at all times. The apparatus consisted of five standard laboratory leverboxes programmed to provide food reward on a continuous reinforcement basis. Upon arrival in the laboratory, Ss were divided into five groups of 12 animals each and placed on a food-deprivation schedule which allowed ad lib feeding for $30 \mathrm{~min}$ every $24 \mathrm{~h}$. The $12 \mathrm{Ss}$ of Group 1 were then trained to leverpress for food reward on a continuous reinforcement schedule. Each Group $1 \mathrm{~S}$ was trained for $30 \mathrm{~min}$ each day, the Ss being under $23^{1 / 2} \mathrm{~h}$ of food deprivation at the start of each daily session. During these training sessions, the Group 2 Ss were paired with the Group 1 Ss such that when each Group $1 \mathrm{~S}$ was placed into its leverbox for training, a Group $2 \mathrm{~S}$ was placed into a second remote box lacking a manipulandum. The feeder on this second box was operated by the lever in the first box. Thus, the Group 2 Ss received exactly the same amount of food in exactly the same temporal sequence as the Group 1 Ss.
The sole difference between the two groups was that the Group 1 Ss learned to leverpress for their food while the Group 2 Ss learned to merely stand by the foodcup in their box and receive food gratis. After the Group 1 Ss had reached asymptotic leverpressing performance levels, they and the paired Group 2 Ss, continued on a daily testing schedule under the same conditions of deprivation and testing as during training.

The three remaining groups (all experimentally naive) were then added to the experiment. The Group $3 \mathrm{Ss}$ were paired with the Group 1 Ss (the experienced leverpressers) such that when each Group $1 \mathrm{~S}$ was placed in its leverbox for its daily 30-min session, a Group $3 \mathrm{~S}$ was placed in a separate leverbox side by side with the Group 1 box and separated from it by a transparent wall. At the same time, the Group 4 Ss were paired with the Group 2 Ss (the experienced eaters) in the same way as were the Ss in Groups 1 and 3 . The boxes for Groups 3 and 4 were equipped with manipulanda and feeders, thus allowing the Ss in Groups 3 and 4 to acquire food-motivated leverpressing behavior on a trial-and-error basis while observing experienced leverpressers and experienced eaters, respectively. In effect, the Group 3 Ss constituted an "observational learning" group and the Group 4 Ss constituted a "social facilitation of learning" group.

The Group 5 Ss were placed individually in another separate leverbox for $30 \mathrm{~min}$ each day and allowed to acquire leverpressing behavior by themselves on a trial-and-error basis, thus consituting a control group exempt from the influence of any other $S$, whether a trained leverpresser or not.

Testing continued for $30 \mathrm{~min}$ each day until all three groups of naive Ss (Groups 3, 4, and 5) had reached asymptotic leverpressing performance levels. The experiment was then terminated.

During the course of the experiment, two Ss were dropped from the study. One was a Group $5 \mathrm{~S}$ that was dropped after 13 days without a single leverpressing response; the other was a Group $3 \mathrm{~S}$ that became ill and died.

\section{RESULTS}

As can be seen in Fig. 1, both the observational learning group and the social facilitation group acquired leverpressing performance much more rapidly than did the control Ss. There was, however, no difference in rate of acquisition between the observational learning group and the social facilitation group. Analysis of variance revealed that the difference between the three groups was highly significant 


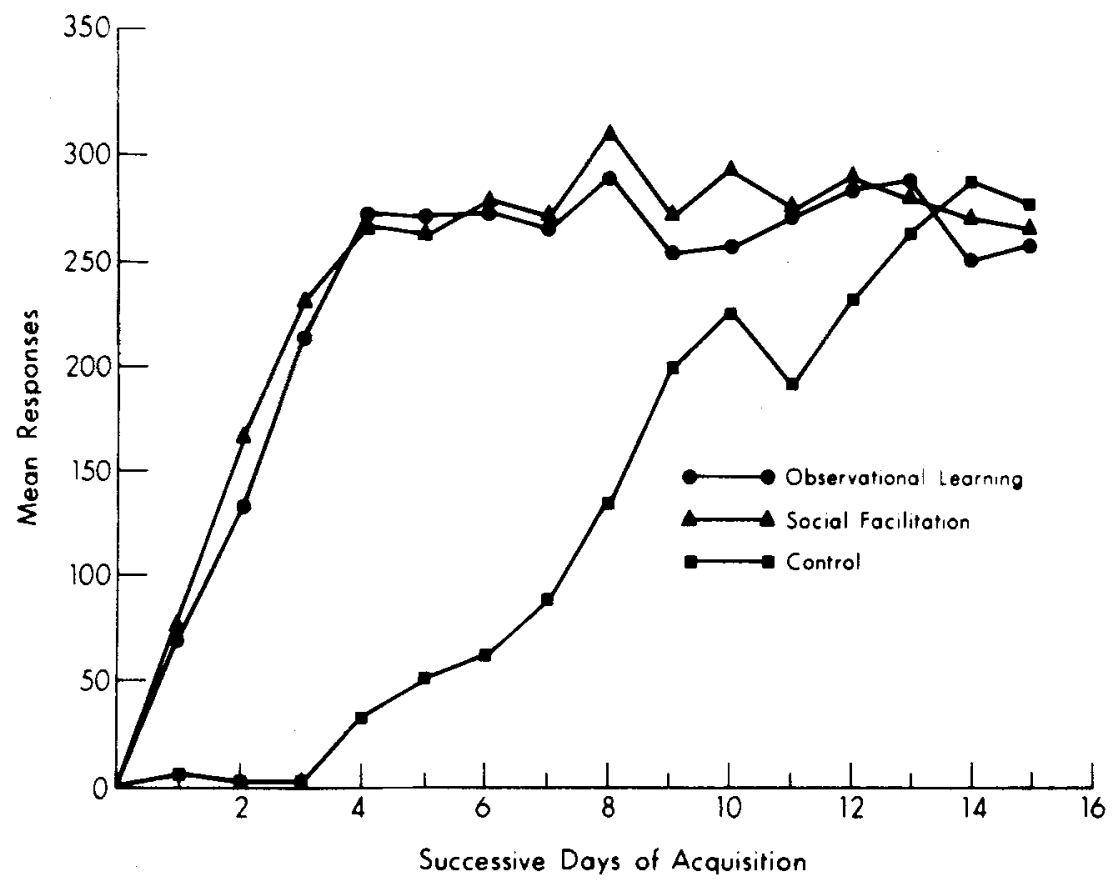

Fig. 1. Mean number of leverpressing responses per 30-min daily test session for "observational learning," social facilitation, and control groups.

$(\mathrm{F}=38.92, \mathrm{df}=2 / 31, \mathrm{p}<.001)$. Tests of individual comparisons showed that the slow rate of learning of the control Ss (Group 5) accounted entirely for this difference and that there was no statistical difference between the observational learning (Group 3) and the social facilitation (Group 4) Ss $[F(3,5)=51.10$, df $=2 / 9, \quad p<.001$ $F(4,5)=64.61, \quad$ df $=2 / 9, \quad \mathrm{p}<.001$ $F(3,4)<1, \mathrm{df}=2 / 9$, n.s. $]$.

\section{DISCUSSION}

The present data indicate that in the laboratory rat, the mere presence of another animal in a learning situation enhances learning without specific imitation or copying. Since previous investigators (e.g., Davitz \& Mason, 1955; Hughes, 1969; Latané, 1969; Tolman, 1968; Treichler et al, 1971; Zajonc, 1965) have reported that the presence of another animal can lead to increases in general activity and to reduction of fear, it is probable that the socially facilitated learning suggested by the present data is the result of such increased activity and fear reduction.

It must be noted that the present portion of the many studies purporting to demonstrate observational learning in a variety of nonprimate species may, in reality, $h$ ave been demonstrating socially facilitated trial-and-error learning instead.

\section{REFERENCES}

BANDURA A Social learning through imitation. In M. R. Jones (Ed.). Nebraska symposium on motivation, 1962. Vol. 10. Lincoln: University of Nebraska Press. 1962. Pp, 211-269.

CHURCH, R. M. Transmission of learned behavior between rats. Joumal of Abnormal \& Social Psychology. 1957, 54. 163-165.

CORSON, J. A. Observational learning of a lever pressing response. Psychonomic Science, 1967, 7, 197-198.

DAVITZ, J. R.. \& MASON, D. J. Socially facilitated reduction of a fear response in rats. Journal of Comparative \& Physiological Psychology, 1955, 48, 149-151.

GILBERT, R. \& BEATON, J. Imitation and cooperation by hooded rats: A preliminary analysis. Psychonomic Science, 1967, 8, 43-44.

GROESBECK, R. W., \& DUER FELDT, $P$. $H$. Some relevant variables in observational learning of the rat. Psychonomic Science, 1971, 22, 41-43.

HUGHES, R. N. Social facilitation of locomotion and exploration in rats British Journal of Psychology, 1969, 60, 385-388.

JOHN, E. R., CHESLER, P., BARTLETT, $F$ \& VICTOR, I. Observation learning in cats. Science, 1968, 159, 1489-1491.

data are somewhat at variance with the findings of Groesbeck \& Duerfeldt (1971), who reported that observational learning Ss acquired a maze-running task in fewer trials than did socially facilitated Ss (Ss that watched demonstrator Ss rewarded on the positive cue card of a maze but never saw the actual performance of the task). This difference in results may be due to the fact that Groesbeck and Duerfeldt's demonstrator Ss were removed from the apparatus after $30 \mathrm{sec}$ and were never present during the actual acquisition trial. In the present study, on the other hand, the experienced eaters were constantly present, thus assuring a more constant and intense level of social facilitation.

The fact that, in the present study, the observational learning and social facilitation groups demonstrated almost identical rates of acquisition further suggests the possibility that social facilitation, rather than direct imitation, may have been of critical importance in a number of previous observational learning experiments. In fact, it seems possible that at least a
KLOPFER, P. H. Social interactions in discrimination learning with special reference to feeding behavior in birds. Behaviour, 1959, 14, 282-299.

LATANÉ, B. Gregariousness and fear in laboratory rats. Joumal of Experimental Social Psychology, 1969, 5, 61-69.

POWELL, $R$. W. Observation learning vs shaping: A replication. Psychonomic Science, 1968, 10, 263-264. Klopfer's empathic leaming hypothesis. Psychonomic Science, 1967, 7, 181-182.

STIM BERT, V. E., SCHAEFFER, R. W., \& GRIMSLEY, D. L. Acquisition of an imitative response in rats. Psychonomic Science, 1966, 5, 339-340.

TOLMAN, $C$. $W$. The role of the companion in social facilitation of animal behavior. In E. C. Simmel, R. A. Hoppe, and G. A. Milton (Eds.), Social facilitation and imitative behavior: Outcome of the 1967 Miami University symposium on social behavior, Boston: Allyn \& Bacon, 1968. Pp. 33-54.

TREICHLER, F. R., GRAHAM, M. M., \& SCHWEIKERT, G. E. Social facilitation of the rat's responding in extinction. Psychonomic Science, 1971, 22, 291-293.

WARDEN, C. J., \& JACKSON, T. A Imitative behavior in the rhesus monkey. Journal of Genetic Psychology, 1935, 46. 103-125.

ZAJONC, R. B. Social facilitation. Science, $1965,149,269 \cdot 274$.
SEXTON, O. J., \& FITCH, J. A test of 